\title{
Resveratrol-induced antinociception is involved in calcium channels and calcium/caffeine-sensitive pools
}

\author{
Xiaoyu Pan ${ }^{1, *}$, Jiechun Chen ${ }^{2, *}$, Weijie Wang ${ }^{3, *}$, Ling Chen ${ }^{4}$, Lin Wang ${ }^{4}$, Quan Ma5 \\ Jianbo Zhang6, Lichao Chen", Gang Wang ${ }^{4}$, Meixi Zhang7,\#, Hao Wu ${ }^{8, \#, ~ R u o c h u a n ~}$ \\ Cheng ${ }^{1, \#}$ \\ ${ }^{1}$ Department of Thyroid Surgery, The First Affiliated Hospital of Kunming Medical University, Kunming, Yunnan Province, \\ China \\ ${ }^{2}$ Department of Neurology, Lianyungang Second People's Hospital, Lianyungang, Jiangsu Province, China \\ ${ }^{3}$ Department of Neurosurgery, Huai'an First People's Hospital, Nanjing Medical University, Huai'an, Jiangsu Province, China \\ ${ }^{4}$ Department of Clinical Pharmacy, Hangzhou First People's Hospital, Nanjing Medical University, Hangzhou, Zhejiang \\ Province, China \\ ${ }^{5}$ Department of Pharmaceutical Sciences, School of Pharmacy and Pharmaceutical Sciences, State University of New York at \\ Buffalo, Buffalo, NY, USA \\ ${ }^{6}$ Present address: Whitehead Institute for Biomedical Research, Cambridge, MA 02142, USA \\ ${ }^{7}$ Pingyang Hospital of Traditional Chinese Medicine, Pingyang, Zhejiang Province, China \\ ${ }^{8}$ Department of Neurology, Wenzhou People's Hospital, Wenzhou, Zhejiang Province, China \\ *These authors contributed equally to this work \\ \#These authors jointly directed this work \\ Correspondence to: Ruochuan Cheng, email: cruochuan@foxmail.com
}

Keywords: resveratrol, calcium channels, antinociception, CaMKII, BDNF

Received: July 22, 2016 Accepted: December 15, $2016 \quad$ Published: December 22, 2016

\section{ABSTRACT}

Resveratrol has been widely investigated for its potential health properties, although little is known about its mechanism in vivo. Previous studies have indicated that resveratrol produces antinociceptive effects in mice. Calcium channels and calcium/caffeine-sensitive pools are reported to be associated with analgesic effect. The present study was to explore the involvement of $\mathrm{Ca}^{2+}$ channel and calcium/ caffeine-sensitive pools in the antinociceptive response of resveratrol. Tail-flick test was used to assess antinociception in mice treated with resveratrol or the combinations of resveratrol with $\mathrm{MK} \mathrm{801}$, nimodipine, $\mathrm{CaCl}_{2}$, ryanodine and ethylene glycol tetraacetic acid (EGTA), respectively. The $\mathrm{Ca}^{2+} / \mathrm{calmodulin}$-dependent protein kinase II (CaMKII) and brain-derived neurotrophic factor (BDNF) levels in the spinal cord were also investigated when treated with the above drugs. The results showed that resveratrol increased the tail flick latency in the tail-flick test, in dosedependent manner. $\mathrm{N}$-methyl-D-aspartate (NMDA) glutamate receptor antagonist MK 801 potentiated the antinociceptive effects of sub-threshold dose of resveratrol at $10 \mathrm{mg} / \mathrm{kg}$. $\mathrm{Ca}^{2+}$ channel blocker, however, abolished the antinociceptive effects of resveratrol. In contrast to these results, EGTA or ryanodine treatment (i.c.v.) potentiated resveratrol-induced antinociception. There was a significant decrease in p-CaMKII and an increase in BDNF expression in the spinal cord when combined with MK 801, nimodipine, ryanodine and EGTA. While an increase in p-CaMKII level and a decrease in BDNF expression were observed when high dose of resveratrol combined with $\mathrm{CaCl}_{2}$. These findings suggest that resveratrol exhibits the antinociceptive effects by inhibition of calcium channels and calcium/caffeine-sensitive pools. 


\section{INTRODUCTION}

Resveratrol (3, 4', 5-trihydroxystilbene), a naturally occurring polyphenol compound naturally present in significant amounts in several plants, has garnered considerable interest given its presence in berries, peanuts, grapes, and red wine [1]. There are two isomers of resveratrol, cis-(Z) and trans-(E) resveratrol. cis-resveratrol was considered biologically inactive; trans-resveratrol seems to be more potent than $c i s$-resveratrol in most of the comparative studies indicating certain stereo-specific activity of the molecule. Previous study also reports that both isoforms possess biological activity [2] and inhibit synthesis of proinflammatory mediators by suppressing cyclooxygenase and lipoxygenase pathways, which suggest that resveratrol may have analgesic activity [3-5].

Calcium $\left(\mathrm{Ca}^{2+}\right)$ channel is a second messenger, which mediates a variety of intracellular functions including gene expression, neurotransmitter release and protein phosphorylation. It has been reported that calcium ion has a physiological role in the inhibition of calcium movement, which contributes to antinociception [6-11]. L-type $\mathrm{Ca}^{2+}$ channel antagonists, nimodipine for example, produces analgesic effect after central and peripheral administration [12-15]. Moreover, the effects of L-type $\mathrm{Ca}^{2+}$ channel inhibitors on nociception differ depending on the drug, dosage, and route of administration and the algesimeter test used [16]. Intracellular $\mathrm{Ca}^{2+}$ pools contained in the endoplasmic reticulum play a major role in tightly regulating the levels of intracellular free $\mathrm{Ca}^{2+}$ in cells. The $\mathrm{Ca}^{2+} /$ calmodulin-dependent protein kinase II (CaMKII) and brain derived neurotrophic factor (BDNF) are involved in the oxaliplatin-induced mechanical allodynia [17], and also plays an important role in brain cells when talked about pain [18].

The present study attempted to find the analgesic effect of resveratrol through $\mathrm{Ca}^{2+}$ ion channels, especially the L-type calcium channels and calcium/caffeine sensitive pool and the regulation of pain associated p-CaMKII and BDNF. We found that calcium ions play in an important role in the analgesic effects of resveratrol, while reducing the intracellular calcium concentration, resulting in significant analgesic effect; on the contrary, the analgesic effect weakened.

\section{RESULTS}

\section{Resveratrol produced antinociceptive effects in the tail flick test}

To confirm the analgesic effect of resveratrol and whether NMDA receptor antagonist MK 801 is involved in the effect of resveratrol, we examined antinociceptive response of resveratrol in the tail-flick test in mice treated with resveratrol or combined with MK 801. Resveratrol at doses of $10 \sim 40 \mathrm{mg} / \mathrm{kg}$ increased the latency to a powerful light beam in the tail-flick test, in a dose-dependent manner $(\mathrm{F}=3.26, p<0.01)$ (Figure 1A). MK 801, an $\mathrm{N}$-methyl-D-aspartate (NMDA) receptor inhibitor, at the dose of $0.5 \mathrm{mg} / \mathrm{kg}$, increased the latency to nociceptive stimulus when combined with resveratrol although it did not induce any behavioral changes when it was used alone $(p<0.01)$ (Figure 1B), which were consistent with the previous studies $[19,20]$.

To further determine whether L-type $\mathrm{Ca}^{2+}$ channels are involved in the antinociception induced by resveratrol, the effect of nimodipine on the inhibition of nociceptive response was examined. Nimodipine at $2.5,5$ and $10 \mathrm{mg} / \mathrm{kg}$ (i.p.) treated alone did not show any effects in the tail flick latency in mice compared to the vehicle-treated group (data now shown), which was in agreement with the previous findings [21]. However, pretreatment with nimodipine potentiated the effects of resveratrol under sub-threshold dose at $10 \mathrm{mg} / \mathrm{kg}(\mathrm{F}=6.49, p<0.05)$ (p.o.) (Figure 1C).

\section{$\mathrm{CaCl}_{2}$ reversed resveratrol's effect, while EGTA and ryanodine potentiated the antinociceptive effects of resveratrol}

The subsequent study explored how the i.c.v. administration of $\mathrm{Ca}^{2+}$ or EGTA (a selective $\mathrm{Ca}^{2+}$ chelator) affects the antinociceptive effects induced by resveratrol. $\mathrm{CaCl}_{2}(25,50,100$ and $200 \mathrm{nmol})$ alone did not induce the antinociception or other behavioral abnormality in the preliminary study. However, i.c.v. administration of $\mathrm{CaCl}_{2}$ at doses of $25 \sim 200 \mathrm{nmol}$ significantly reversed the antinocicetive responses induced by resveratrol at $20 \mathrm{mg} / \mathrm{kg}$ $(\mathrm{F}=3.21, p<0.05)$ (Figure 2A). By contrast, i.c.v. injection of $\operatorname{EGTA}(5,15$ and $30 \mathrm{nmol})$ increased the tail flick latency when combined with the $10 \mathrm{mg} / \mathrm{kg}$ resveratrol $(\mathrm{F}=2.80$, $p<0.05$ ) (Figure 2B), but it did not show any behavioral changes when it was used alone in our preliminary study.

Previous in vitro studies indicated ryanodine inhibits $\mathrm{Ca}^{2+}$ release from intracellular microsomal pools $[22,23]$. The present study explored whether inhibition of $\mathrm{Ca}^{2+}$ release from microsomal pools by ryanodine involves resveratrol's antinociceptive effects. Ryanodine $(0.25 \sim 2 \mathrm{nmol}$, i.c.v. $)$ used alone was not observed the antinociceptive or toxic effects in our preliminary study. However, ryanodine at doses of $0.25,0.5,1$ and $2 \mathrm{nmol}$ increased the tail flick latency in dose-dependent manner when combined with $10 \mathrm{mg} / \mathrm{kg}$ resveratrol $(\mathrm{F}=4.91$, $p<0.05$ ) (Figure 2C).

\section{The effect of resveratrol on p-CaMKII and BDNF expression in the spinal cord}

As shown in Figure 3A and 3B, resveratrol at doses of 10,20 and $40 \mathrm{mg} / \mathrm{kg}$ decreased $\mathrm{p}$-CaMKII expression $(\mathrm{F}=7.03, p<0.05)$ and increased BDNF level in the spinal cord $(\mathrm{F}=3.65, p<0.05)$. MK 801 at doses of 0.1 and $0.5 \mathrm{mg} / \mathrm{kg}$ used alone did not show to affect both of 
p-CaMKII and BDNF expression (data not shown). However, the effects on $\mathrm{p}-\mathrm{CaMKII}$ and BDNF expression were potentiated when combined with low dose of resveratrol at $10 \mathrm{mg} / \mathrm{kg}$, i.e. decreased p-CaMKII and increased BDNF levels in the spinal cord were observed in the spinal cord as shown in Figure $3 \mathrm{C}$ and $3 \mathrm{D}(\mathrm{F}=7.34$, $p<0.05 ; \mathrm{F}=6.89, p<0.05)$.

\section{Nimodipine potentiated the effects of resveratrol on p-CaMKII and BDNF expression in the spinal cord}

Low dose of resveratrol at $10 \mathrm{mg} / \mathrm{kg}$ did not affect both p-CaMKII and BDNF expression as shown in Figure 3. However, pretreatment with nimodipine at doses of $2.5,5$ and $10 \mathrm{mg} / \mathrm{kg}$ potentiated resveratrol's effects on $\mathrm{p}-\mathrm{CaMKII}$ and BDNF expression in the spinal cord, in a dose-dependent manner $(\mathrm{F}=7.75, p<0.05 ; \mathrm{F}=7.66$, $p<0.05$; Figure 4A and 4B). But these doses of nimodipine did show any effects on the above two proteins expression when it was used alone in our preliminary data.

\section{$\mathrm{CaCl}_{2}$ reversed, but EGTA potentiated resveratrol's effects on pCaMPKII and BDNF expression in the spinal cord}

To confirm the effects of resveratrol on p-CaMKII and BDNF expression in the spinal cord are related to the calcium channel, $\mathrm{CaCl}_{2}$ and $\mathrm{Ca}^{2+}$ channel selective chelator EGTA were administered by i.c.v and the effects of them on levels of p-CaMKII and BDNF were observed. The results showed that the i.c.v. pre-injection $\mathrm{CaCl}_{2}$ reversed $20 \mathrm{mg} / \mathrm{kg}$ resveratrol-induced decreased p-CaMKII expression, i.e. p-CaMKII expression was increased after i.c.v. pre-treatment with $\mathrm{CaCl}_{2}(\mathrm{~F}=3.19, p<0.05)$ (Figure 5A). Pre-injection with $\mathrm{CaCl}_{2} 30 \mathrm{~min}$ before $20 \mathrm{mg} / \mathrm{kg}$ resveratrol treatment induced a dose-dependent decrease in BDNF expression in the spinal cord $(\mathrm{F}=7.53, p<0.05)$ (Figure 5B). However, pretreatment with different doses of selective $\mathrm{Ca}^{2+}$ channel chelator EGTA potentiated the effect of low dose of resveratrol $(10 \mathrm{mg} / \mathrm{kg})$ on p-CaMKII expression, which showed a significant dose-dependent decreased $\mathrm{p}$-CaMKII levels in the spinal cord $(\mathrm{F}=7.03$,
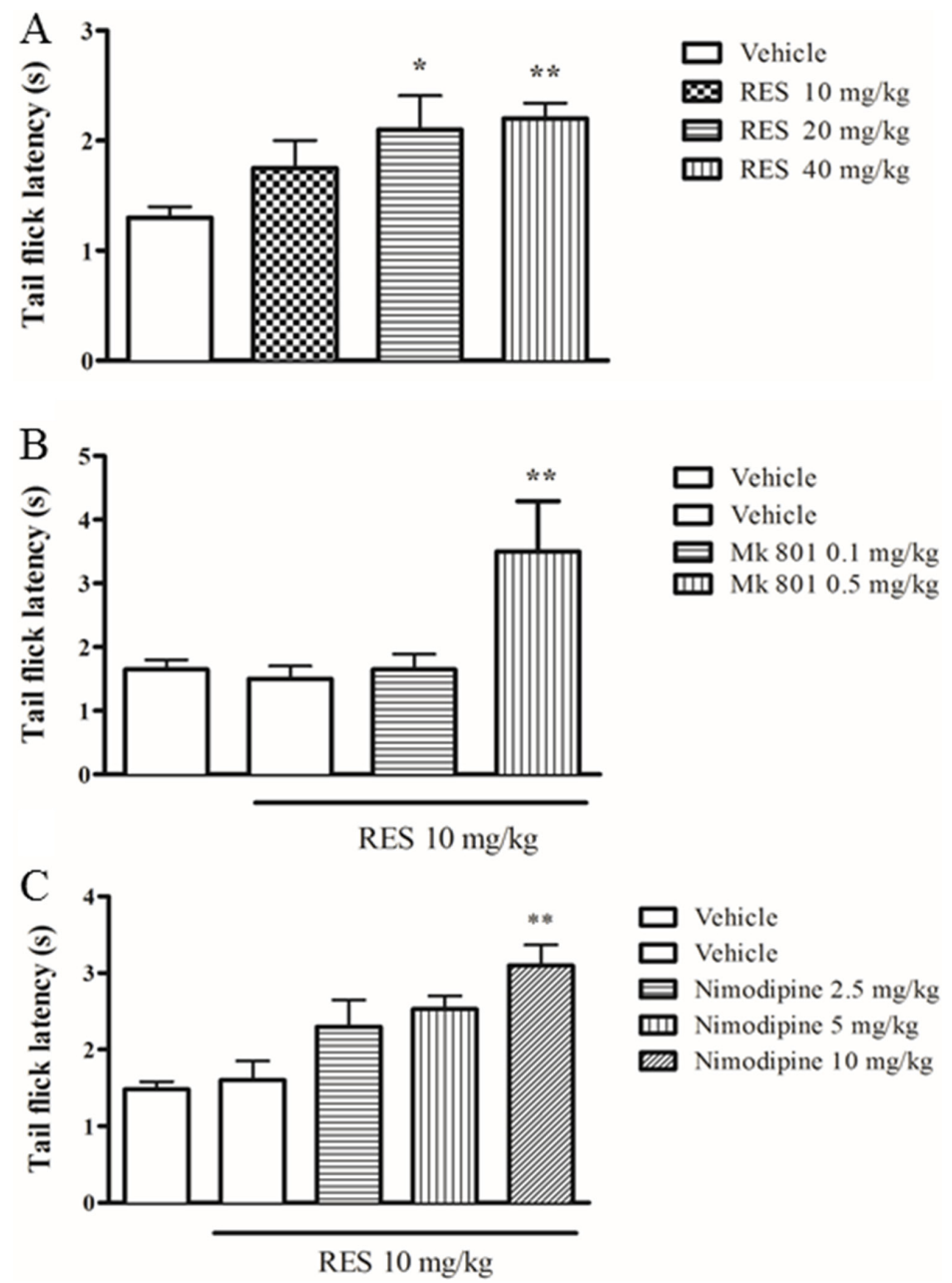

Figure 1: The effect of resveratrol on tail flick latency in mice. Mice were administered vehicle, resveratrol (10, 20, $40 \mathrm{mg} / \mathrm{kg}, \mathrm{p} . \mathrm{o}$.) $1 \mathrm{~h}$ before testing. Mk 801 (0.1 and $0.5 \mathrm{mg} / \mathrm{kg}$, i.p.) and nimodipine $(2.5,5$ and $10 \mathrm{mg} / \mathrm{kg}$, i.p.) were administered $30 \mathrm{~min}$ before resveratrol treatment. Mean $\pm \operatorname{SEM}, n=8 .{ }^{*} p<0.05$ and ${ }^{*} p<0.01$, compared to the vehicle + resveratrol $(10 \mathrm{mg} / \mathrm{kg})$ group. 
$p<0.05$ ) (Figure 5C). Pretreatment of EGTA also potentiated low dose of resveratrol induced BDNF expression $(\mathrm{F}=7.66$, $p<0.05$ ) (Figure 5D), which confirmed the extracellular calcium ions participated resveratrol's effects on noxious stimulation.

\section{Ryanodine potentiated the effect of resveratrol on p-CaMKII and BDNF expression}

To verify the involvement of the calcium ions released from calcium/caffeine-sensitive pools in the effects of resveratrol, the expression of $\mathrm{p}$-CaMKII and $\mathrm{BDNF}$ in the spinal cord were detected when pretreatment with ryanodine $30 \mathrm{~min}$ before resveratrol was given. Figure $6 \mathrm{~A}$ showed that ryanodine significantly enhanced low dose of resveratrol's effect on p-CaMKII, i.e. significantly decreased p-CaMKII expression when pretreatment with ryanodine $(\mathrm{F}=6.93, p<0.05)$. However, BDNF expression was increased significantly when low dose of resveratrol combined with ryanodine $(\mathrm{F}=5.62$, $p<0.05$ ) (Figure 6B). However, different doses of ryanodine used alone did induce any effects on these two proteins expression (data not shown).

\section{DISCUSSION}

Pain affects about $20 \%$ of the world's population, which is a great economic and social burden to community $[24,25]$. Neuropathic pain is the main type of pain. Most of neuropathic pain is due to nervous system damage
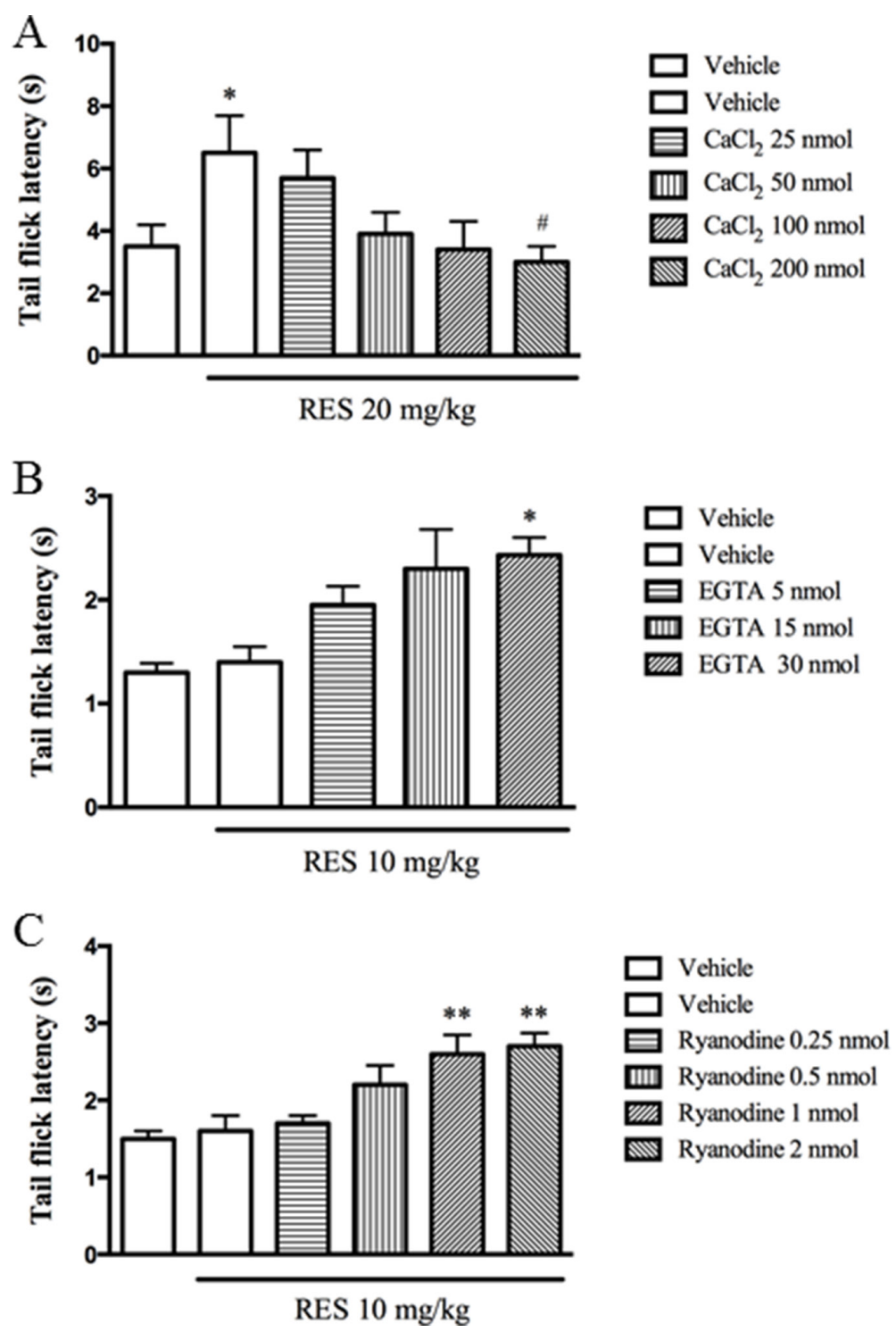

Figure 2: $\mathrm{CaCl}_{2}$ reversed resveratrol's effect, while EGTA and ryanodine potentiated the antinociceptive effects of resveratrol. $\mathrm{CaCl}_{2}(25,50,100$ and $200 \mathrm{nmol}$, i.c.v), $\operatorname{EGTA}(5,15$ and $30 \mathrm{nmol}$, i.c.v) and ryanodine $(0.25,0.5,1$ and 2 nmol, i.c.v) were administered 30 min before resveratrol treatment. Mean \pm SEM, $n=8$. ${ }^{*} p<0.05$ and ${ }^{* *} p<0.01$, compared to the vehicle + resveratrol (10 or $20 \mathrm{mg} / \mathrm{kg}$ ) group. 
and dysfunction [26]. Due to the central and peripheral neuralgia complex mechanisms, therapeutic agents that can be used is limited, and these drugs often require large doses, which greatly limits their use. Currently, the use of analgesic drugs can only alleviate the $40-50 \%$ of pain for $30-40 \%$ of patients [27].

Calcium ions $\left(\mathrm{Ca}^{2+}\right)$ enter into cell through voltagegated calcium channels (VGCCs) excitement, and VGCCs mediated calcium channel is an initial step of presynaptic nerve terminals neurotransmitter release. Because of their special role in calcium signaling, VGCCs is an important target for the treatment of pain. $\mathrm{Ca}^{2+}$ as an intracellular second messenger is involved in a series of functional activities, including electrophysiological activity, neurotransmitter release, protein phosphorylation and gene expression [21]. Central $\mathrm{Ca}^{2+}$ is closely related to the neurotransmitter transmission of pain, such as tailflick test. Oral administration of L-type calcium channel antagonists and nimodipine can improve the effect on pain threshold [14, 28]. Furthermore, research has shown that $\mathrm{Ca}^{2+}$ /caffeine sensitive microsomal pool, calmodulin and CaMKIIK participate in $\beta$-endorphin and morphine analgesia [29]. Increase in the $\mathrm{Ca}^{2+}$ levels can antagonize the analgesic effect of opioid. $\mathrm{Ca}^{2+}$ and $\mathrm{Ca}^{2+}$ vectors such as X-537A and A23187 will shift $\mathrm{Ca}^{2+}$ from extracelluar to intracellular, thereby increasing the intracellular $\mathrm{Ca}^{2+}$ concentration, decreased analgesic effect of opioids $[30,31]$. Intracerebral injection of $\mathrm{Ca}^{2+}$ chelator EGTA can enhance the analgesic effect of opioids $[32,33] . \mathrm{Ca}^{2+}$ is very easy to penetrate from the NMDA receptor channel into intracellular $[34,35]$. NMDA receptor channel has two distinct gated modes of ligands and voltage-gated. In the resting potential $\mathrm{Mg}^{2+}$ channel was blocked by voltagegated $[37,38,39]$. When the membrane depolarization, NMDA receptor channel opening, calcium ions enter into intracellular. Some researchers found that nerve compression can be reversed by resveratrol in a dosedependent manner by mechanical hypersensitivity and thermal hyperalgesia tests [36]. The present study suggested that resveratrol significantly increased the pain threshold in mice in the tail-flick test. The N-methyl-Daspartate (NMDA) receptor inhibitor MK 801 increased the latency to nociceptive stimulus when combined with resveratrol, which are consistent with the previous studies.

Given low dose of L-type calcium channel antagonist nimodipine does not produce analgesic effects [21], but nimodipine significantly enhanced resveratrol's analgesic effects with subthreshold dose $(10 \mathrm{mg} / \mathrm{kg})$. Nimodipine antagonizes L-type calcium channel to reduce intracellular calcium ion concentration, which are in agreement with our findings that suggested that nimodipine enhanced the analgesic effect of resveratrol. The present results also suggested that intracerebral injection of $\mathrm{CaCl}_{2}$ reversed the analgesic effects of resveratrol, but selective calcium ion chelator EGTA enhanced the analgesic effect of resveratrol. Previous studies demonstrated that the reduced concentration of calcium ions in neurons could produce an analgesic effect,
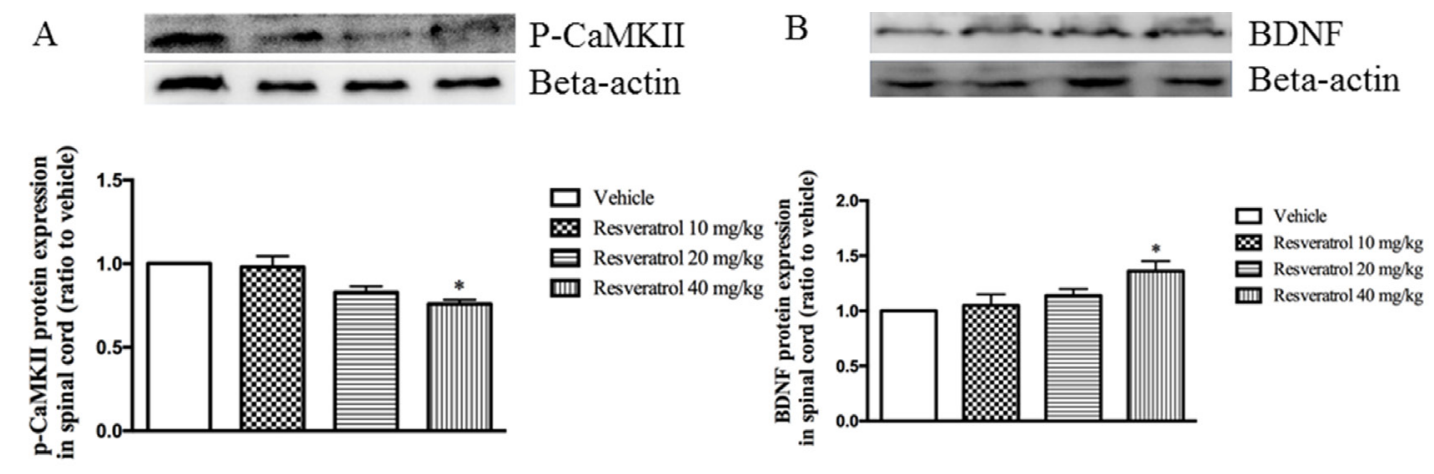
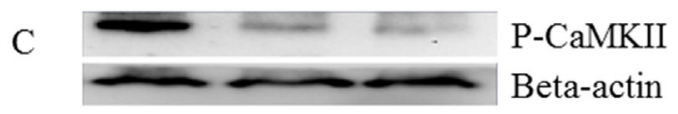

$\mathrm{D}$

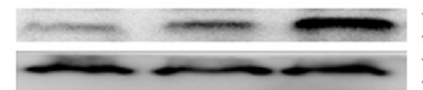

BDNF

Beta-actin

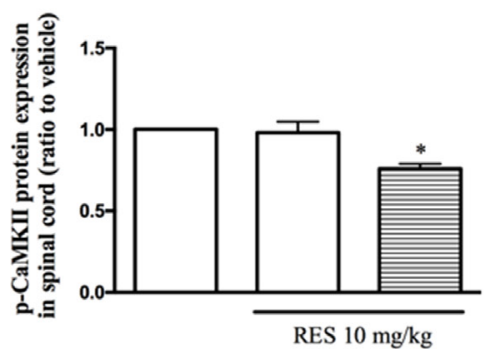

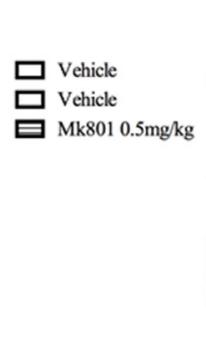
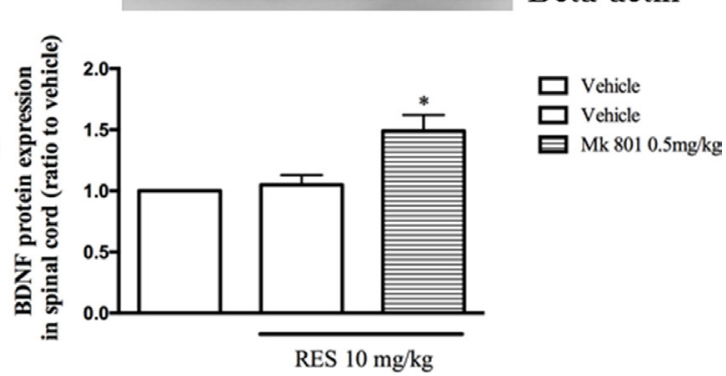

Figure 3: The effect of resveratrol on p-CaMKII and BDNF expression in the spinal cord (A and $\mathbf{B})$ and Mk 801 potentiated resveratrol's effect on p-CaMKII and BDNF expression (C and D). Mean $\pm \mathrm{SEM}, n=8 .{ }^{*} p<0.05$, compared to the vehicle + resveratrol $(10 \mathrm{mg} / \mathrm{kg})$ group. 
while increased intracellular calcium ion concentration could antagonize the analgesic effect [40]. Contrary to intracerebral injection of calcium ion chelator EDTA, direct injection of $\mathrm{CaCl}_{2}$ can increase synaptic calcium concentration, and enable neurons to have function [41]. In our present study, $\mathrm{CaCl}_{2}$ was injected to the cerebral ventricle, which increased extracellular calcium concentration, then increased the calcium ion permeable membranes into cells, thereby increasing the intracellular calcium ion concentration, blocking the analgesic effect of resveratrol. Similar to L-type calcium channels antagonist, intracerebral injection of calcium ion selective chelators EGTA reduced the concentration of extracellular calcium and calcium ions to enter cell membrane, leading to the reduction of intracellular calcium concentration, thereby enhancing the analgesic effect of resveratrol. Indeed, calcium concentration in neurons affects not only by calcium ions regulation that permeable membrane from extracellular into intracellular, but also by calcium ions regulation that influences of calcium stores by inositol triphosphate and ryanodine receptor in cells. Ryanodine receptor plays an important role in the regulation of calcium store and microsomal calcium release [23]. Saeki et al. [42] found that the brain-type ryanodine receptor expression in the hamster is always calcium and caffeine sensitive. In our experiments, intracerebral injection of ryanodine significantly enhanced the analgesic effects of resveratrol. Studies have shown that ryanodine blocks the release of calcium from calcium/caffeine sensitive microsomal pool [23]. Injection with ryanodine allows intracellular release of calcium ions to decrease the store of calcium, which enhances the analgesic effect of resveratrol. In addition, ryanodine also reduces the rate of calcium ions from the extracellular into the intracellular [43], which also helps to enhance its potentiation on the analgesic effect of resveratrol.
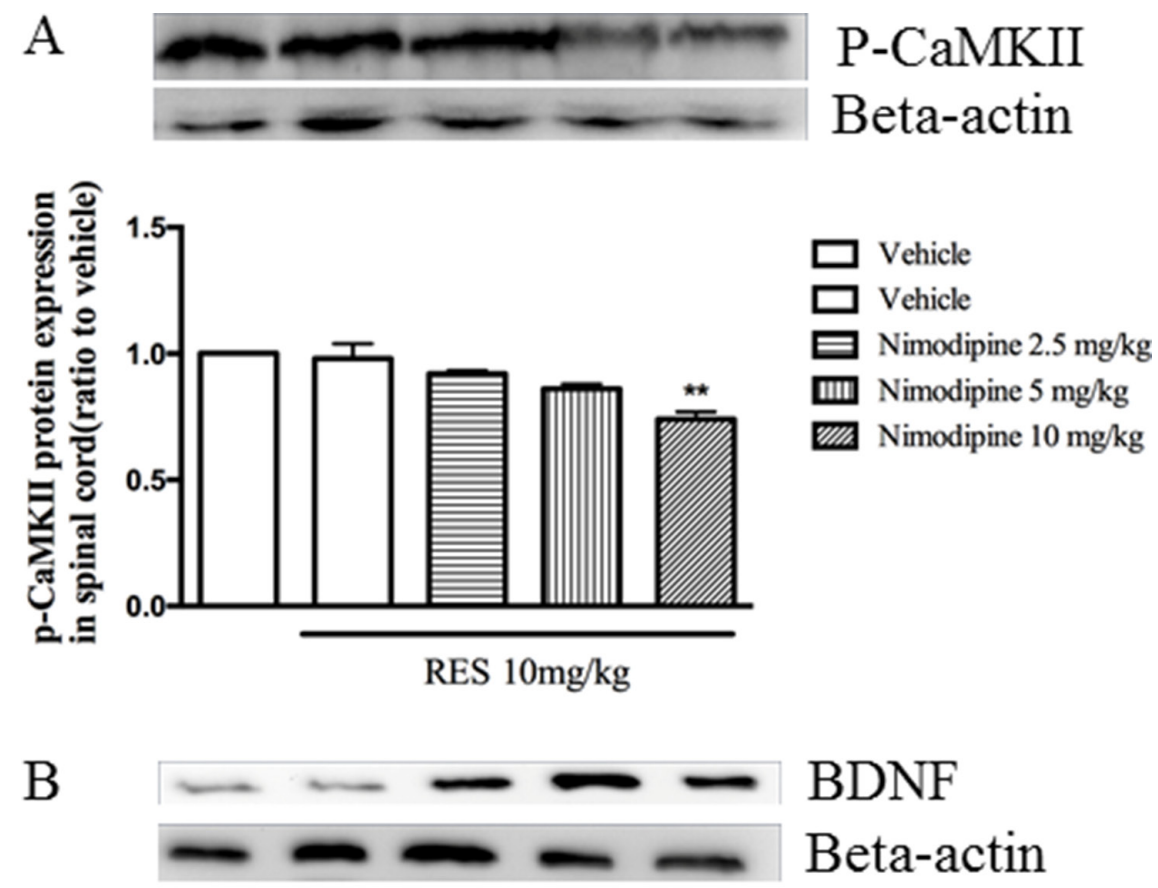

\title{
BDNF Beta-actin
}

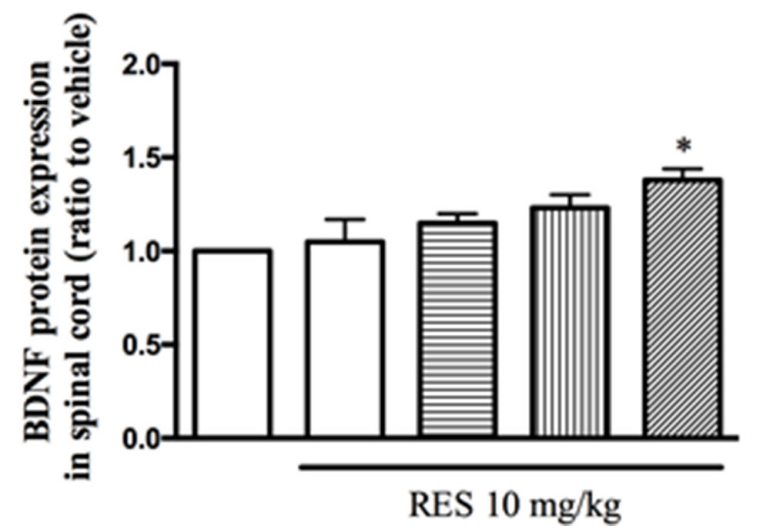

\author{
$\square$ Vehicle \\ $\square$ Vehicle \\ D Nimodipine $2.5 \mathrm{mg} / \mathrm{kg}$ \\ IIII Nimodipine $5 \mathrm{mg} / \mathrm{kg}$ \\ שII Nimodipine $10 \mathrm{mg} / \mathrm{kg}$
}

RES $10 \mathrm{mg} / \mathrm{kg}$

Figure 4: Nimodipine potentiated the effects of resveratrol on p-CaMKII and BDNF expression in the spinal cord. Mean \pm SEM, $n=8 . * p<0.05$ and $p<0.01$, compared to the vehicle+resveratrol $(10 \mathrm{mg} / \mathrm{kg})$ group. 
CaMKII is a serine/threonine kinase involved in a variety of neurological function. When intracellular $\mathrm{Ca}^{2+}$ signal markedly enhances [44], calcium ions will bind to $\mathrm{Ca}^{2+}$ binding sites by calmodulin after activation of CaMKII phosphorylation, which causes pain. Studies have shown that CaMKII first focuses on the area of pain transmission, such as superficial spinal dorsal horn and dorsal root ganglia [45]. Animal studies have shown that it is involved in the formation and transfer of peripheral neuropathic pain [46]. In the present study, when given resveratrol or administered simultaneously MK 801, nimodipine, EGTA and ryanodine, the expression of p-CaMKII in the spinal cord was significantly reduced; and when the intracerebral administration of $\mathrm{CaCl}_{2}$, the p-CaMKII expression in the spinal cord was significant increased. Previous studies suggested that excessive $\mathrm{Ca}^{2+}$ or CaMKII over phosphorylation might produce some degree of neurotoxicity to the cells and inhibit some biochemical pathways such as CREB and BDNF signaling [47]. When excessive $\mathrm{Ca}^{2+}$ flows into intracellular by L-type voltage-gated calcium channels or NMDA receptors, BDNF transcription was inhibited $[48,49,50,51]$. Previous work suggested that peripheral nerve injury, such as the tail-flick test, is an expression of neuropathic pain, which is alleviated when the increase in BDNF release [52]. Our findings suggest that BDNF expression may directly inhibit the perceptive behaviors by the tail flick test. Pre-administration with MK 801, nimodipine, EGTA and ryanodine, BDNF expression in the spinal cord was significantly increased, while the intracerebral injection of $\mathrm{CaCl}_{2}$ decreased the $\mathrm{BDNF}$ expression. However, further studies may be needed to confirm whether the nociceptive effect of resveratrol can be inhibited by BDNF directly or indirectly.

In summary, the increase in the intracellular $\mathrm{Ca}^{2+}$ can potentiate resveratrol's analgesic effect significantly, while the increase in the intracellular $\mathrm{Ca}^{2+}$ reversed resveratrol's effect on nociception. CaMKII and BDNF in the spinal cord participate the effects of resveratrol on the nociceptive response. These findings implicate that calcium channels and the calcium/caffeine-sensitive pool are involved in the analgesic effects of resveratrol.

\section{MATERIALS AND METHODS}

\section{Animals}

Male ICR mice (25-30 g) bred in the Animal Center of Shanghai Branch of Chinese Academy of Sciences were used. On arrival, the animals were housed under standard laboratory conditions, maintained on a $12 \mathrm{~h}$ natural light/ dark cycle and free access to food and water. Ambient temperature and humidity were maintained at $23-25^{\circ} \mathrm{C}$ and $50 \pm 10 \%$ respectively. Before the tests, animals were acclimatized to laboratory conditions for 1 week. The experiments were performed with 10 mice per treatment group according to a randomized schedule between 10:00 $\mathrm{h}$ and 18:00 h. All experiments were conducted in accordance with the National Institutes of Health Guide for Care and Use of Laboratory Animals (Publication No. 85-23, revised 1985), and approved by the Wenzhou Medical College Committee on Animal Care and Use.
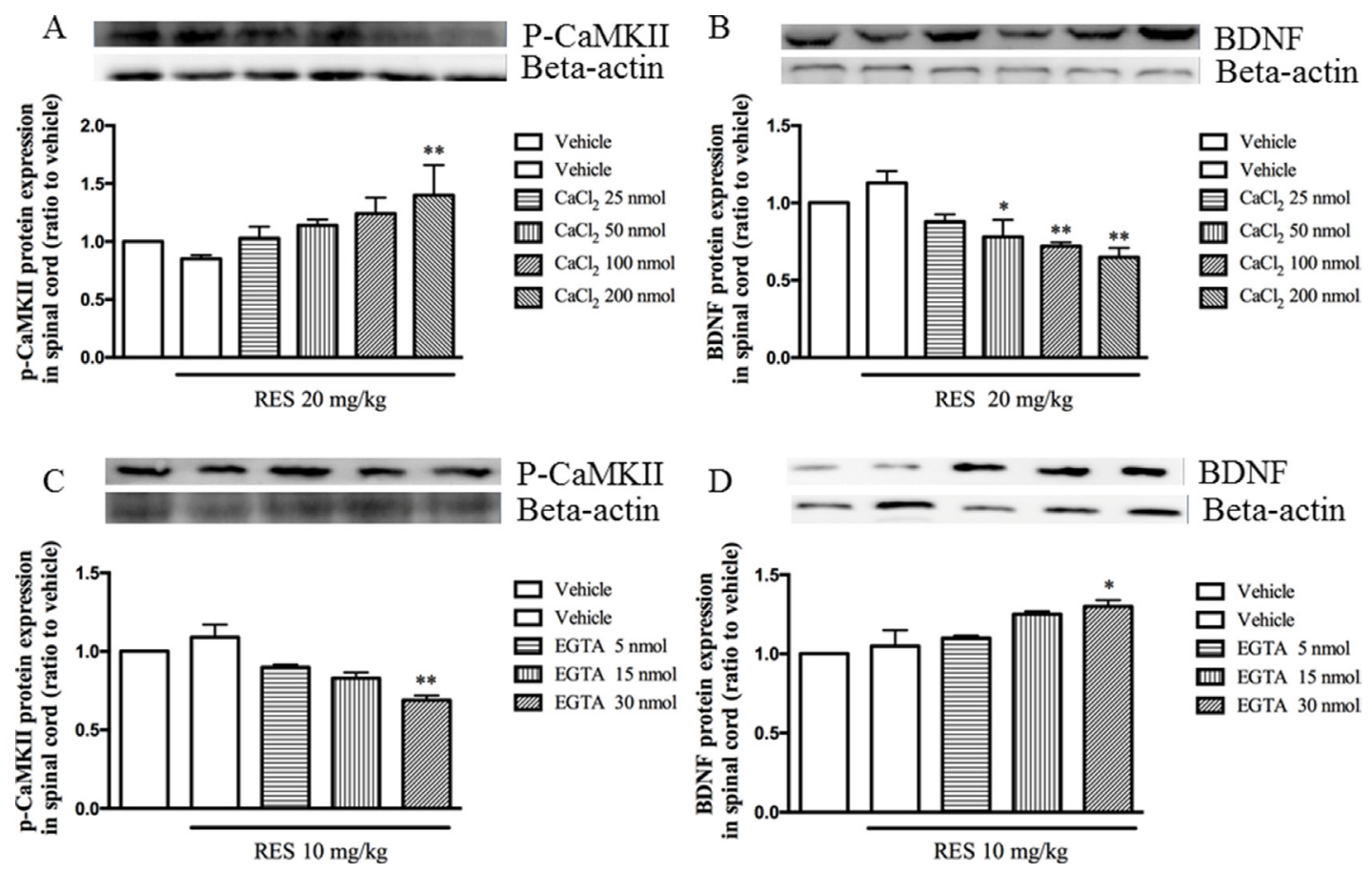

Figure 5: CaCl2 reversed, but EGTA potentiated resveratrol's effects on pCaMPKII and BDNF expression in the spinal cord. Mean $\pm \mathrm{SEM}, n=8 .{ }^{*} p<0.05$ and $p<0.01$, compared to the vehicle + resveratrol $(20 \mathrm{or} 10 \mathrm{mg} / \mathrm{kg}) \mathrm{group}$. 


\section{Drugs and chemicals}

The drugs and chemicals used included resveratrol (Wuhan St. Tianyu Technology Co., Ltd., China), nimodipine (Enzo Biochem, Inc., USA), $\mathrm{CaCl}_{2}$ (Quzhou Juhua Reagent Co., Ltd., China), ethylene glycolbis (ß-aminoethyl-ether)-N, N, N', N'-tetraacetic acid (EGTA)(Sinopharm Chemical Reagent Co., Ltd., China), ryanodine (Tocris Bioscience, UK), Mk 801 (Sigma, USA). For oral administration (via gavage, p.o. with a vloume of $10 \mathrm{ml} / \mathrm{kg}$ ), transe-resveratrol was dissolved in $0.5 \%$ sodium carboxymethyl cellulose (CMC-Na) and diluted to the desired concentration on the day of testing [53]. The other drugs and chemicals were dissolved in $0.9 \%$ saline with the exception of nimodipine, which was dissolved in one drop of ethanol and diluted with saline, and EGTA, which was dissolved in sterilized $\mathrm{H}_{2} \mathrm{O}$ [21]. $\mathrm{CMC}-\mathrm{Na}$ or saline was used as vehicle control in all the experiments. Nimodipine and Mk 801 were injected i.p. in a volume of $10 \mathrm{ml} / \mathrm{kg}$, while $\mathrm{CaCl}_{2}, \mathrm{EGTA}$ and ryanodine were given by i.c.v. administration.

\section{Drug treatment}

The i.c.v. injections were carried out as described previously $[54,55]$.Vehicle or drugs were injected in a volume of $1 \mu$ into the mouse hippocampus CA1 [56]. In short, during anesthesia, mice were grasped firmly by the loose skin behind the head. A 27-gauge needle attached to a $50 \mu \mathrm{l}$ Hamilton syringe was inserted perpendicularly through the skull into the brain, no more than $2 \mathrm{~mm}$, and $1 \mu \mathrm{l}$ of solution was injected. The injection site was $2 \mathrm{~mm}$ from either side of the midline drawn through the anterior base of the ears. Injections were performed into the hippocampus CA1. To verify the injection sites, a volume of $10 \mu \mathrm{l}$ of $1 \%$ methylene blue was injected and the brains were sectioned and studied histologically.

\section{Behavioral tests}

The tail flick test is an acute model of pain, which was used to assess the anti-nociceptive effect of the drugs by measuring the latency of response to a light beam [57].

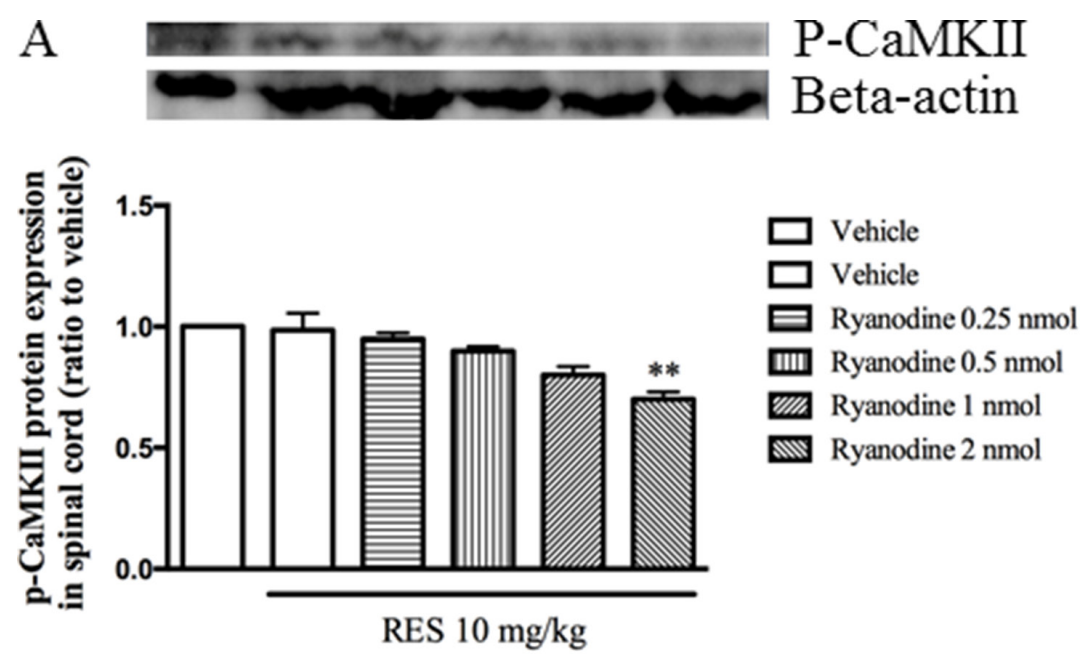

B
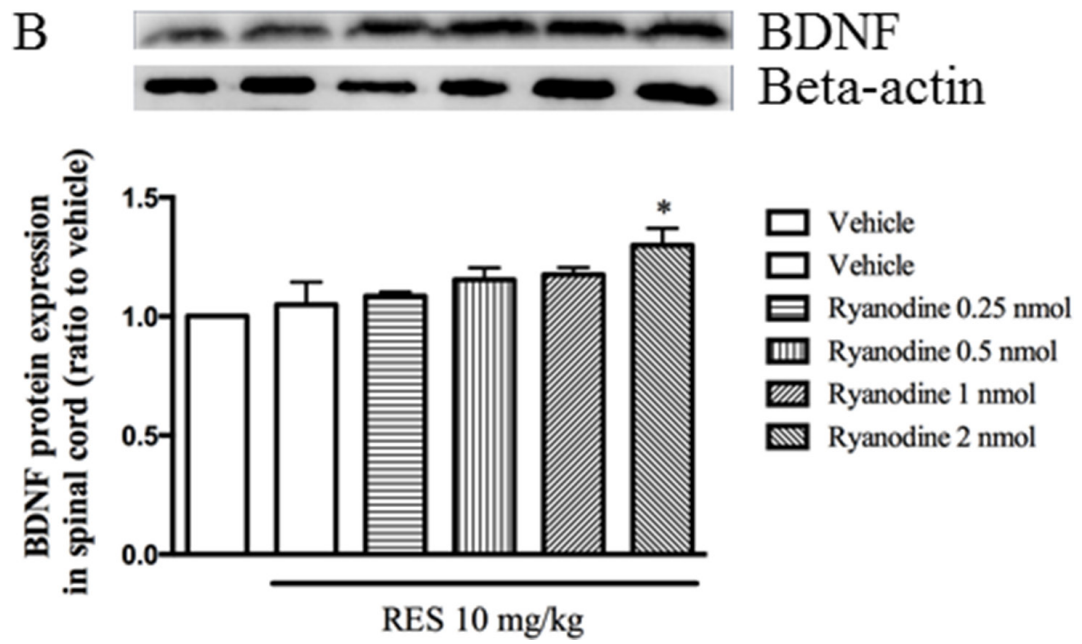

Figure 6: Ryrandine potentiated the effects of resveratrol on p-CaMKII and BDNF expression in the spinal cord. Mean \pm SEM, $n=8 .{ }^{*} p<0.05$ and $p<0.01$, compared to the vehicle+resveratrol $(10 \mathrm{mg} / \mathrm{kg})$ group. 
In this method, animal tail was exposed to a powerful light beam and the response latency period for flicking the tail off the beam was recorded [58]. We applied radiant heat to the tail at $5-8 \mathrm{~cm}$ from the tip by using a tail flick apparatus. Tail flick latency time was estimated as the time from the onset of the heat exposure to the withdrawal of the tail. They adjusted the intensity of radiant heat to yield the baseline latencies of 2-4 second. In order to avoid tissue damages the heat stimulus was discontinued after 7 second (Cut off point $=7 \mathrm{sec}$ ). In this study, tail flicking test was performed $30 \mathrm{~min}$ after injection (20).

\section{Immunoblot analysis}

Tissue samples from lumbar enlargement were dissected and stored at $-80^{\circ} \mathrm{C}$ until analysis. The supernatant fluid containing $60 \mu \mathrm{g}$ of protein was electrophoresed in a polyacrylamide gel and blotted onto PVDF membranes. The membranes were incubated with $5 \%$ non-fat dried milk in Tris buffer saline containing Tween 20 for 1.5 hours at room temperature $\left(25^{\circ} \mathrm{C}\right)$ and then incubated with rabbit anti-CaMKII monoclonal antibody (1: 1000, Cell Signaling Technology, USA) or with rabbit anti-phosphorylated CaMKII polyclonal antibody (1: 1000, Cell Signaling Technology, USA) or with rabbit anti-BDNF polyclonal antibody (1: 1000, Abcam, USA) at $4^{\circ} \mathrm{C}$ overnight. Following three washing with TBST, the membrane was then incubated with an HRP-conjugated monkey anti-rabbit IgG (1:10000, SantaCruz) for CaMKII or p-CaMKII or BDNF for 1 hour at room temperature. Finally, membranes were washed again with Tris buffer saline containing Tween 20 to remove unbound secondary antibodies and visualized using ChemiDoc XRS System. The blots were then incubated with a polyclonal rabbit anti- $\beta$-actin antibody (1:1000, Cell Signaling Technology, USA) as the loading controls. Each experiment was repeated at least once and the same results were obtained in all cases. Six animals per group were used in the Western blotting analysis. The density of specific bands was measured using a computerized image analysis system.

\section{Statistical analysis}

All data were presented as mean \pm standard error (SEM) or and statistically analyzed with repeated measures analysis of variances (ANOVA) followed by Dunnett's post hoc tests. Differences were considered to be statistically significant at $P<0.05$.

\section{CONFLICTS OF INTEREST}

The authors declare that they have no conflicts of interest.

\section{GRANT SUPPORT}

This project was granted by the Natural Science Foundation of Zhejiang Province (NO.15H090003), Public Applied Research of Zhejiang Province (NO.2016F82SA100042), Opening Project of Zhejiang Provincial Top Key Discipline of Pharmaceutical Sciences (No. YKFJ2-013) and Health and Technology Project of Yunnan Province (No. 2014ns 175).

\section{REFERENCES}

1. Mullin GE. Red wine, grapes, and better health - resveratrol. Nutr Clin Pract. 2011; 26:722-723.

2. Orallo F. Comparative studies of the antioxidant effects of cis- and trans-resveratrol. Curr Med Chem. 2006; 13:87-98.

3. MacCarrone M, Lorenzon $\mathrm{T}$, Guerrieri P, Agro AF. Resveratrol prevents apoptosis in K562 cells by inhibiting lipoxygenase and cyclooxygenase activity. Eur J Biochem. 1999; 265:27-34.

4. Subbaramaiah K, Chung WJ, Michaluart P, Telang N, Tanabe T, Inoue H, Jang M, Pezzuto JM, Dannenberg AJ. Resveratrol inhibits cyclooxygenase- 2 transcription and activity in phorbol ester-treated human mammary epithelial cells. J Biol Chem. 1998; 273:21875-21882.

5. Jang M, Cai L, Udeani GO, Slowing KV, Thomas CF, Beecher CW, Fong HH, Farnsworth NR, Kinghorn AD, Mehta RG, Moon RC, Pezzuto JM. Cancer chemopreventive activity of resveratrol, a natural product derived from grapes. Science. 1997; 275:218-220.

6. Schmidt WK, Way EL. Hyperalgesic effects of divalent cations and antinociceptive effects of a calcium chelator in naive and morphine-dependent mice. J Pharmacol Exp Ther. 1980; 212:22-27.

7. Vanegas H, Schaible H. Effects of antagonists to highthreshold calcium channels upon spinal mechanisms of pain, hyperalgesia and allodynia. Pain. 2000; 85:9-18.

8. Heinke B, Balzer E, Sandkuhler J. Pre- and postsynaptic contributions of voltage-dependent $\mathrm{Ca} 2+$ channels to nociceptive transmission in rat spinal lamina I neurons. Eur J Neurosci. 2004; 19:103-111.

9. Galeotti N, Bartolini A, Ghelardini C. Role of intracellular calcium in acute thermal pain perception. Neuropharmacology. 2004; 47:935-944.

10. Chen JQ, Zhang YQ, Dai J, Luo ZM, Liang SP. Antinociceptive effects of intrathecally administered huwentoxin-I, a selective $\mathrm{N}$-type calcium channel blocker, in the formalin test in conscious rats. Toxicon. 2005; 45:15-20.

11. Weiss N, De Waard M. [Voltage-dependent calcium channels at the heart of pain perception]. Med Sci. 2006; 22:396-404.

12. Del Pozo E, Ruiz-Garcia C, Baeyens JM. Analgesic effects of diltiazem and verapamil after central and peripheral 
administration in the hot-plate test. Gen Pharmacol. 1990; 21:681-685.

13. Miranda HF, Pelissier T, Sierralta F. Analgesic effects of intracerebroventricular administration of calcium channel blockers in mice. Gen Pharmacol. 1993; 24:201-204.

14. Wong $\mathrm{CH}, \mathrm{Wu} \mathrm{WH}$, Zbuzek VK. Hypotension does not alter the antinociceptive effect of nifedipine. Life Sci. 1998; 63:PL343-348.

15. Todorovic SM, Pathirathna S, Meyenburg A, JevtovicTodorovic V. Mechanical and thermal anti-nociception in rats after systemic administration of verapamil. Neurosci Lett. 2004; 360:57-60.

16. Prado WA. Involvement of calcium in pain and antinociception. Braz J Med Biol Res. 2001; 34:449-461.

17. Shirahama M, Ushio S, Egashira N, Yamamoto S, Sada H, Masuguchi K, Kawashiri T, Oishi R. Inhibition of Ca2+/ calmodulin-dependent protein kinase II reverses oxaliplatininduced mechanical allodynia in rats. Mol Pain. 2012; 8:26.

18. Ogawa A, Dai Y, Yamanaka H, Iwata K, Niwa H, Noguchi K. $\mathrm{Ca}(2+) /$ calmodulin-protein kinase IIalpha in the trigeminal subnucleus caudalis contributes to neuropathic pain following inferior alveolar nerve transection. Exp Neurol. 2005; 192:310-319.

19. Yin Q, Lu FF, Zhao Y, Cheng MY, Fan Q, Cui J, Liu L, Cheng W, Yan CD. Resveratrol facilitates pain attenuation in a rat model of neuropathic pain through the activation of spinal Sirt1. Reg Anesth Pain Med. 2013; 38:93-99.

20. Sharma S, Kulkarni SK, Chopra K. Effect of resveratrol, a polyphenolic phytoalexin, on thermal hyperalgesia in a mouse model of diabetic neuropathic pain. Fundam Clin Pharmacol. 2007; 21:89-94.

21. Liang JH, Wang XH, Liu RK, Sun HL, Ye XF, Zheng JW. Buspirone-induced antinociception is mediated by L-type calcium channels and calcium/caffeine-sensitive pools in mice. Psychopharmacology. 2003; 166:276-283.

22. Rousseau E, Smith JS, Meissner G. Ryanodine modifies conductance and gating behavior of single $\mathrm{Ca} 2+$ release channel. Am J Physiol. 1987; 253:C364-368.

23. McPherson PS, Kim YK, Valdivia H, Knudson CM, Takekura H, Franzini-Armstrong C, Coronado R, Campbell KP. The brain ryanodine receptor: a caffeinesensitive calcium release channel. Neuron. 1991; 7:17-25.

24. Gureje O, Von Korff M, Simon GE, Gater R. Persistent pain and well-being: a World Health Organization Study in Primary Care. JAMA. 1998; 280:147-151.

25. Blyth FM, March LM, Brnabic AJ, Jorm LR, Williamson M, Cousins MJ. Chronic pain in Australia: a prevalence study. Pain. 2001; 89:127-134.

26. Baron R. Mechanisms of disease: neuropathic pain-a clinical perspective. Nat Clin Pract Neurol. 2006; 2:95-106.

27. Backonja M, Woolf CJ. Future directions in neuropathic pain therapy: closing the translational loop. Oncologist. 2010; 2:24-29.
28. Miranda HF, Bustamante D, Kramer V, Pelissier T, Saavedra H, Paeile C, Fernandez E, Pinardi G. Antinociceptive effects of Ca2+ channel blockers. Eur J Pharmacol. 1992; 217:137-141.

29. Smith FL, Stevens DL. Calcium modulation of morphine analgesia: role of calcium channels and intracellular pool calcium. J Pharmacol Exp Ther. 1995; 272:290-299.

30. Vocci FJ, Jr, Welch SP, Dewey WL. Differential effects of divalent cations, cation chelators and an ionophore (A23187) on morphine and dibutyryl guanosine 3': 5'-cyclic monophosphate antinociception. J Pharmacol Exp Ther. $1980 ; 214: 463-466$.

31. Chapman DB, Way EL. Modification of endorphin/ enkephalin analgesia and stress-induced analgesia by divalent cations, a cation chelator and an ionophore. Br J Pharmacol. 1982; 75:389-396.

32. Kakunaga T, Kaneto H, Hano K. Pharmacologic studies on analgesics. VII. Significance of the calcium ion in morphine analgesia. J Pharmacol Exp Ther. 1966; 153:134-141.

33. Ben-Sreti MM, Gonzalez JP, Sewell RD. Effects of elevated calcium and calcium antagonists on 6,7-benzomorphaninduced analgesia. Eur J Pharmacol. 1983; 90:385-391.

34. Ascher P, Nowak L. The role of divalent cations in the $\mathrm{N}$-methyl-D-aspartate responses of mouse central neurones in culture. J Physiol. 1988; 399:247-266.

35. MacDermott AB, Mayer ML, Westbrook GL, Smith SJ, Barker JL. NMDA-receptor activation increases cytoplasmic calcium concentration in cultured spinal cord neurones. Nature. 1986; 321:519-522.

36. Baur JA, Ungvari Z, Minor RK, Le Couteur DG and de Cabo R. Are sirtuins viable targets for improving healthspan and lifespan? Nat Rev Drug Discov. 2012; 11:443-461.

37. McBain CJ, Mayer ML. N-methyl-D-aspartic acid receptor structure and function. Physiol Rev. 1994; 74:723-760.

38. Mayer ML, Westbrook GL, Guthrie PB. Voltage-dependent block by $\mathrm{Mg} 2+$ of NMDA responses in spinal cord neurones. Nature. 1984; 309:261-263.

39. Nowak L, Bregestovski P, Ascher P, Herbet A, Prochiantz A. Magnesium gates glutamate-activated channels in mouse central neurones. Nature. 1984; 307:462-465.

40. Miranda HF, Paeile C. Interactions between analgesics and calcium channel blockers. Gen Pharmacol. 1990; 21:171-174.

41. Dogrul A, Yesilyurt O. Effects of intrathecally administered aminoglycoside antibiotics, calcium-channel blockers, nickel and calcium on acetic acid-induced writhing test in mice. Gen Pharmacol. 1998; 30:613-616.

42. Saeki K, Obi I, Ogiku N, Hakamata Y, Matsumoto T. Characterization of brain-type ryanodine receptor permanently expressed in Chinese hamster ovary cells. Life Sci. 1998; 63:575-588.

43. Friel DD, Tsien RW. A caffeine- and ryanodine-sensitive Ca2+ store in bullfrog sympathetic neurones modulates effects of Ca2+ entry on [Ca2+]i. J Physiol. 1992; 450:217-246. 
44. Eisenach JC, Zhang Y, Duflo F. alpha2-adrenoceptors inhibit the intracellular $\mathrm{Ca} 2+$ response to electrical stimulation in normal and injured sensory neurons, with increased inhibition of calcitonin gene-related peptide expressing neurons after injury. Neuroscience. 2005; 131:189-197.

45. Carlton SM. Localization of CaMKIIalpha in rat primary sensory neurons: increase in inflammation. Brain Res. 2002; 947:252-259.

46. Dai Y, Wang H, Ogawa A, Yamanaka H, Obata K, Tokunaga A, Noguchi K. Ca2+/calmodulin-dependent protein kinase II in the spinal cord contributes to neuropathic pain in a rat model of mononeuropathy. Eur J Neurosci. 2005; 21:2467-2474.

47. Tao X, Finkbeiner S, Arnold DB, Shaywitz AJ, Greenberg ME. $\mathrm{Ca}^{2+}$ influx regulates BDNF transcription by a CREB family transcription factor-dependent mechanism. Neuron. 1998; 20:709-26.

48. Lauterborn JC, Rivera S, Stinis CT, Hayes VY, Isackson PJ, Gall CM. Differential effects of protein synthesis inhibition on the activity-dependent expression of BDNF transcripts: evidence for immediate-early gene responses from specific promoters.J Neurosci. 1996; 16:7428-7436.

49. West AE, Chen WG, Dalva MB, Dolmetsch RE, Kornhauser JM, Shaywitz AJ, Takasu MA, Tao X, Greenberg ME. Calcium regulation of neuronal gene expression. Proc Natl Acad Sci USA. 2001; 98:11024-11031.

50. Ghosh A, Carnahan J, Greenberg ME. Requirement for BDNF in activity-dependent survival of cortical neurons. Science. 1994; 263:1618-1623.

51. Tao X, Finkbeiner S, Arnold DB, Shaywitz AJ, Greenberg ME. Ca2+ influx regulates BDNF transcription by a CREB family transcription factor-dependent mechanism. Neuron. 1998; 20:709-726.

52. Kolarow R, Brigadski T, Lessmann V. Postsynaptic secretion of BDNF, NT-3 from hippocampal neurons depends on calcium calmodulin kinase II signaling and proceeds via delayed fusion pore opening. J Neurosci. 2007; 27:10350-10364.

53. Xu Y, Wang Z, You W, Zhang X, Li S, Barish PA, Vernon MM, Du X, Li G, Pan J, Ogle WO. Antidepressant-like effect of trans-resveratrol: Involvement of serotonin and noradrenaline system. Eur Neuropsychopharmacol. 2010; 20:405-413.

54. Haley TJ, McCormick WG. Pharmacological effects produced by intracerebral injection of drugs in the conscious mouse. Br J Pharmacol Chemother. 1957; 12:12-15.

55. Zhao X, Xu Y, Zhao Q, Chen CR, Liu AM, Huang ZL. Curcumin exerts antinociceptive effects in a mouse model of neuropathic pain: descending monoamine system and opioid receptors are differentially involved. Neuropharmacology. 2012; 62:843-854.

56. Hafeshjani ZK, Karami M, Biglarnia M. Nitric oxide in the hippocampal cortical area interacts with naloxone in inducing pain. Indian J Pharmacol. 2012; 44:443-447.

57. Tsiklauri N, Nozadze I, Gurtskaia G, Berishvili V, Abzianidze E, Tsagareli M. Tolerance induced by nonopioid analgesic microinjections into rat's periaqueductal gray and nucleus raphe. Georgian Med News. 2010; :47-55.

58. Abbasnezhad A, Khazdair MR, Kianmehr M. The role of nitric oxide on the oxytocin induce analgesia in mice. Iran $\mathrm{J}$ Basic Med Sci. 2016; 19:238-244. 